\title{
ESCENA
}

Publicación semestral. ISSN 2215-4906

Volumen 79 - Número 1

Julio - Diciembre 2019

\section{La autoregulación emocional de las juventudes a través de la música}

Emotional self-regulation from youth through music

Anna María Fernández

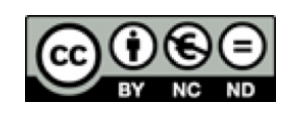

Esta obra está bajo una licencia Creative Commons Reconocimiento-No comercial-Sin Obra Derivada 


\title{
La autoregulación emocional de las juventudes a través de la música
}

\author{
Emotional self-regulation from youth through music \\ Anna María Fernández ${ }^{1}$ \\ Universidad Autónoma Metropolitana \\ México
}

Recibido: 27 de julio de 2018 Aprobado: 11 de febrero de 2019

\begin{abstract}
Resumen
Este trabajo presenta la relación entre música, emociones y juventud. El objetivo es realizar un acercamiento al gusto por la música, los géneros de música que escuchan las juventudes y las principales emociones. Además de por qué gusta la música y para qué sirve en sus vidas. Se parte de la idea de la importancia de la música en la vida cotidiana juvenil y su incidencia en el mundo emocional, sobre otros ámbitos, como el cognitivo o el comportamental. Se realizaron grupos focales con adolescentes y jóvenes. El resultado muestra la diversidad del gusto musical juvenil y se afirma que la música sirve, en primer lugar, para relajarse. En segundo lugar, sentirse bien y, en tercer lugar, divertirse. Lo cual muestra una sabia autorregulación emocional, más allá de la identidad o del puro entretenimiento y diversión que los estudios de juventud señalan.
\end{abstract}

Palabras clave: música; juventud; géneros musicales; emociones; vida cotidiana

\begin{abstract}
This work presents the relationship between music, emotions and youth. The aim is to approach the taste for music, the music genres that youth listen to, and the main emotions, as well as why they like music and what it is used for in their lives. It starts from the idea of the importance of music in the daily life of young people and its impact on the emotional world, on other areas, such as cognitive or behavioral. Focus groups were conducted with adolescents and young people. The result shows the diversity of youthful musical taste, and it is stated that music serves firstly to relax, secondly to feel good, and thirdly to have fun. This shows a wise emotional self-regulation, beyond the identity or pure entertainment and fun that youth studies point out.
\end{abstract}

Keywords: music; youth; musical genres; emotions; daily life

1 Profesora e investigadora de la Universidad Autónoma Metropolitana, Ciudad de México. Doctora Antropología Cultural Universidad de Barcelona. Correo electrónico: fpam1721@correo.xoc.uam.mx 


\section{Introducción}

"Somos criaturas musicales de forma innata desde lo más profundo de la naturaleza humana" (Koelsch, citado en Punset, 2011, p. 1)

La música es importante para la vida de las personas y de los colectivos sociales. Entre otras cosas, crea y recrea, expresa y transmite valores, significados y, sobre todo, emociones. La música, sin lugar a dudas, es parte de la vida y la vida está en la música. Incluso, se dice que la música está viva. Nos acompaña toda la existencia y está presente en los momentos cumbres y solemnes, como los ritos de pasaje. Así como en la vida cotidiana, mientras realizamos nuestras actividades más comunes y rutinarias. Como manifestación artística es producto de un contexto espacio temporal, lo refleja o construye; es influida por el mismo y, a su vez, lo influye también. Por su parte, la juventud es también una construcción social, en cada tiempo y lugar, que destaca por su carácter procesual (Fernández, 2003). Más allá de ser grupo de coetáneos o de etapa de formación, como se suele decir, se trata de una generación o grupo social que comparte la vida en su contemporaneidad, el contexto social y la música que, en ese momento, reproduzca y escuche.

Así, la música como manifestación artística y cultural crea y recrea valores o antivalores, identidades, ideologías y, sobre todo, para los efectos de este texto, diremos que emociones. Se trata de una forma de observar y expresar el mundo en el que se vive (Hormigos \& Martín, 2004). Es parte del aprendizaje social, producción y reproducción cognitiva; además de creadora de climas emocionales; un medio para compartir vivencias y experiencias; unifica, libera y divierte; expresa siempre (Carballo, 2006). Sobre todo, se la señala como parte del consumo e identidad juvenil, además de la creatividad que significa. Así como de la creación y recreación de ideologías y valores (Hormigos, 2004). Incluso, colabora en la construcción identitaria de los jóvenes. Por su parte, la juventud es básica y fundamental, a juzgar por los estudios al respecto o con solo mirar a nuestro alrededor.

Las emociones son procesos físicos, mentales, neurofisiológicos, bioquímicos, psicológicos y culturales. En ocasiones reactivos y básicos, otras veces, comprenden una gran complejidad. Se trata de sentimientos breves y abruptos, que conllevan manifestaciones físicas. En general, duran poco tiempo y se acompañan de agitación física, al activarse el sistema nervioso central (Marina citado por Fernández, 2011; Filliozat citado Fernández, 2011). Por su parte, los sentimientos son emociones que están culturalmente codificadas, nombradas y perduran en el tiempo. El placer o el dolor se queda en la mente y el cuerpo (Fernández, 2011). La emoción está ligada a la música y viceversa. La musicoterapia es conocida para la salud, la creatividad y el aprendizaje, ya que la música llega, incluso, a lo más profundo de la psique humana que las palabras. Así también, su empleo es cada vez más extenso en la 
salud física (Waisburd \& Erdmenger, 2007; Muñoz, 2008; Sacks, 2015). También es sabida la incidencia de la música en las emociones, a la vez, que las emociones en inciden en el tipo de música que se escucha. Esto es, en ocasiones se elige y escucha determinado tipo de música según el estado de ánimo de quien la escucha, por otra parte, puede darse la relación inversa, que consiste en desarrollar un determinado estado de ánimo o emoción, a partir de la escucha de cierto estilo musical (Alaminos, 2014). Varios estudios revelan cómo las melodías lentas, con cadencia descendente provocan sensaciones de tristeza. Mientras las de cadencia ascendente aportan sentimientos estimulantes. Hay tipos de música que relajan y reducen la ansiedad (Alcalde, 2017) como otros que estimulan lo contrario.

De hecho, el ser asiduo de un estilo musical provoca cambios de ánimo y puede ser una defensa contra el estrés o la depresión. Incluso, debido a que produce dopamina -hormona que combate el estrés-, restaura tejidos dañados, estimula neuronas y colabora, de cierta manera, en el control emocional. Lo mismo que ciertos tipos de música se asocian a ciertas drogas y otros tipos, al alcohol; esta asociación no solo no soluciona nada, sino que acrecienta la problemática de la salud personal y social (León, 2011). Es que "la música no solo genera buenas vibraciones, también puede causar ansiedad, aburrimiento e incluso ira" (Ball, 2014, p. 1). Todo ello, a través de la activación de determinadas zonas cerebrales y la liberación de ciertos neurotransmisores, tales como la dopamina o adrenalina. Es más, según Koelsch (citado por Punset, 2011) nada impacta tanto en el cerebro como la música, ya que afecta el movimiento, la memoria y las emociones, pues contribuye a cambiar el estado de ánimo. Resulta poderosa para activar las estructuras emocionales en el cerebro, como señala la neurociencia, además de modular la actividad cerebral emocional (citado por Punset, 2011, p. 2). También, une a la gente, crea cohesión social, para lo que, hay quien dice fue creada; la atenuación de conflictos y la convivencia grupal (Olivera, 2017). Sin olvidar el disfrute y bienestar personal que genera o puede generar.

Finalmente, el vocablo música proviene de musa, las hijas de Zeus, según la mitología griega, inspiradoras del arte y la cultura, quienes deleitaban a los dioses del Olimpo con cantos y música. La palabra emoción, por su parte, proveniente del latín y significa movimiento o impulso, lo que mueve hacia algo. Por lo que, ambos términos denotan movimiento y acción. De hecho, en el diccionario de la Real Academia de la Lengua Española (RAE), música es "musicar o poner música a un texto para poder ser cantado" (RAE, 2018). Mientras que emoción es "alteración de ánimo intensa o pasajera, agradable o desagradable" (RAE, 2018). De nuevo, nos encontramos ante el movimiento y la acción. No obstante, lo que hay que averiguar es hacia dónde conduce, o sea, en qué dirección: hacia el bienestar o malestar; hacia el desarrollo o el deterioro; hacia la felicidad o el sufrimiento. Algo de lo cual se tratará de dilucidar a lo largo de estas páginas. 


\section{Objetivos}

Una vez clarificada la importancia de la música en la vida, el destacado papel de esta en la juventud y su fundamental relación con las emociones, es necesario acotar lo que aquí se pretende. Es decir, el objetivo central, que es estudiar y dilucidar el gusto juvenil por la música, los estilos musicales más populares entre este grupo de edad, en la actualidad, y especialmente, las emociones que según la percepción de los jóvenes se producen al escuchar los diferentes tipos de música. Además del por qué gusta y para qué sirve la música. El foco está en revisar el efecto de la música en las audiencias juveniles más que la música en sí. Esto es, el lenguaje musical es parte de la relación comunicativa, une, comunica, influencia. Es que, sin lugar a dudas, como se ha mencionado y se seguirá afirmando a lo largo de este trabajo, la música afecta, influye, provoca reacciones emotivas, mueve y conmueve como las emociones mismas, o a través de ellas.

\section{Metodología}

La comunicación musical se sitúa en un determinado contexto y es, fundamentalmente, expresión. Posee una función eminentemente social, afecta al auditorio y a los espectadores, a la vez que produce emociones, que van de lo agradable a lo desagradable, de lo satisfactorio a lo insatisfactorio, incluida la catarsis, la liberación o la contestación. Las tradicionales investigaciones del discurso y del lenguaje se extienden hacia los estudios encaminados a dilucidar los efectos e influencias en los receptores. Por una parte, la influencia causada, y por otra parte, la libertad de los oyentes en relación con el discurso musical, en este caso, y su posible intención de convencimiento o influencia social. En fin, que la música, según la teoría de la comunicación, parte de un emisor que la produce, un mensaje que comunica y un receptor que la recibe, sobre el cual se producen efectos en distintas dimensiones, una de las cuales es, sin duda, la emocional. El auditorio muestra opinión alrededor de los gustos y experiencias musicales, a partir de sus expresiones. Una suerte de discurso que, como toda narración, trata de una reorganización vivencial, conocimiento humano, organización cognitiva, evocación memorística, pero, sobre todo, narración experiencial y emocional (Bruner, 1991; Smorti, 2001).

Para realizar este estudio, se creó un corpus, a través de la realización de varios grupos de enfoque con jóvenes de edades comprendidas entre los 12 y 25 años. La elección de los grupos focales como técnica de investigación social aplicada del método cualitativo fue porque permite aprehender las expresiones de las percepciones experienciales, a través de su manifestación discursiva oral y escrita. Esto, a través de un cuestionario escrito antes y la participación oral durante el mismo. Se trata de lenguajes complementarios, el primero, escrito, configurado desde la individualidad y la reflexión que ofrece la narrativa misma y el escribir. El segundo, la participación oral acompañada de la polifonía colectiva 
de voces argumentativas en torno a un tema, que se trenzan y destrenzan. Así, se obtiene discurso oral y escrito; individual personal e individual público, en el curso de la interacción social misma. Un discurso, por supuesto, con su ideología y en su contexto. Resulta, fundamentalmente, un acto social e interacción social comunicativa, formas de acción social, ya sea oral o escrita (Van Dijk, 2001). Se tiene presente la complejidad del objeto y sujeto de estudio, pues se trata de jóvenes, como se ha dicho entre 12 y 25 años, quienes, a través de su expresión, exponen su percepción, sensación y emoción-difícil de aprehender y traducir- sobre la música -intangible y compleja de interpretar-. No obstante, se trata de un acercamiento cualitativo y no representativo; descriptivo e interpretativo, que únicamente busca acercarse al objeto y sujeto de estudio como aproximación inicial, obtener información general, significativa, reflexiva, emotiva al respecto fundamentalmente.

Los grupos de enfoque son herramientas recurso y procedimiento con objeto de recolectar información para interpretar y analizar (Fernández, 2009). A esto, hay que añadir que también pueden ser vistos como técnicas expresivas, que colaboran con el participante en el sentido de inducir a reflexionar, externar, compartir y volver a reflexionar, desde ideas a sentimientos sobre un tema concreto. Por lo cual, y más allá de obtener insumos para quien investiga, ofrece un medio de expresión y reflexión a quien participa. Son una suerte de confesión pública que combina lo sociológico y lo psicológico al producir, reflejar, captar, explicar y analizar las vivencias personales y las experiencias colectivas, los discursos, las acciones, las ideologías, las conductas, los recuerdos, las expectativas, los valores y actitudes, desde las miradas y voces de sus protagonistas o de ciertos colectivos sociales; un microcosmos de un macrocosmos (lbáñez, 1986; Ortí, 1996).

La información recabada, a través de estos grupos, fue analizada según campos semánticos. Esto es, a partir de un conjunto de palabras relacionadas por su significado, que comparten un sema o ciertas características comunes; lexemas relacionados recíprocamente a través de un parentesco semántico significativo. Se eligió este enfoque porque es posible investigar el corpus seleccionado y ubicado en su contexto, mediante cuestionarios y discursos en los grupos de enfoque (Coseriu citado en Corrales, 1991; Trier citado en Corrales, 1991). Se analizan los semas específicos según características de contenido sobre una base significativa común, un archisemema, que los delimita y conjuga semas diferenciadores, todo ello de forma amplia y general (Corrales, 1991).

De esta manera, se revisa la información obtenida por medio de la identificación de palabras alrededor de la música, en particular, sobre determinadas cuestiones centradas en el tema y objetivos de la investigación aquí presentada. Se configuran los campos semánticos que aparecen por medio del análisis y se realiza, sobre ellos, una interpretación. Para ello, se emplean los términos obtenidos en los cuestionarios escritos, del testimonio oral 
de los grupos, o en su defecto, la descomposición de unidades fraseológicas en vocablos. También se tiene en cuenta su frecuencia cuantitativa de aparición. Se realizó una lectura intensiva y profunda de la información, para configurar un inventario léxico nucleado en campos y subcampos semánticos, a partir de las ideas temáticas principales, los elementos léxicos, las asociaciones, las relaciones y el contexto. En todo caso, el trabajo -como se ha mencionado con anterioridad- es descriptivo, interpretativo y, en la medida de lo posible, reflexivo. Más que responder a teorías, lo que desea es invitar a la participación, a compartir la información y, especialmente, a la reflexión - de quien participa, quien escribe y quien lee-. Como se verá en el apartado final de conclusiones, los resultados del estudio fueron más allá de las ideas y objetivos inicialmente planteados en el diseño de este estudio.

Los grupos focales tuvieron lugar en la ciudad de México en el año 2017, tres en una secundaria: primero, segundo y tercer grado en la Escuela Secundaria número 250 Jesús M. Sotelo e Inclán, con un total de 41 adolescentes participantes: 19 hombres y 22 mujeres de entre 12 y 15 años de edad. Otros tres en un $\mathrm{CCH}$-primer semestre, tercer semestre y quinto semestre en el Colegio de Ciencias y Humanidades/Plantel Vallejo en los cuales estuvieron presentes 28 jóvenes: 15 hombres y 13 mujeres entre 15 y 18 años. Finalmente, dos en la Universidad Autónoma Metropolitana/Plantel Xochimilco con 17 hombres y 16 mujeres, quienes sumaron un total de 33 participantes con una edad que va de los 18 a los 25 años

Tabla 1. Muestra de la población de grupos en secundaria

\begin{tabular}{|c|c|c|c|c|c|c|}
\multicolumn{1}{c|}{} & \multicolumn{2}{c|}{ Hombres } & \multicolumn{2}{c|}{ Mujeres } & \multicolumn{2}{c|}{ Total } \\
\hline Grado & Número & Porcentaje & Número & Porcentaje & Número & Porcentaje \\
\hline 1 & 9 & 21,95 & 5 & 12,20 & 14 & 34,15 \\
\hline 2 & 6 & 14,63 & 4 & 9,76 & 10 & 24,39 \\
\hline 3 & 4 & 9,76 & 13 & 31,71 & 17 & 41,46 \\
\hline Total & 19 & 46,34 & 22 & 53,66 & 41 & 100 \\
\hline
\end{tabular}

Fuente: Elaboración propia. 
Tabla 2. Muestra de la población de grupos en $\mathrm{CCH}$

\begin{tabular}{|c|c|c|c|c|c|c|}
\cline { 2 - 7 } \multicolumn{1}{|c|}{} & \multicolumn{2}{c|}{ Hombres } & \multicolumn{2}{c|}{ Mujeres } & \multicolumn{2}{c|}{ Total } \\
\hline Grado & Número & Porcentaje & Número & Porcentaje & Número & Porcentaje \\
\hline 1 & 5 & 17,86 & 5 & 17,86 & 10 & 35,71 \\
\hline 3 & 4 & 14.29 & 5 & 17,86 & 9 & 32,14 \\
\hline 5 & 6 & 21.43 & 3 & 10,71 & 9 & 32,14 \\
\hline Total & 15 & 53,57 & 13 & 46,43 & 28 & 100 \\
\hline
\end{tabular}

Fuente: Elaboración propia.

Tabla 3. Muestra de la población de los grupos de universidad

\begin{tabular}{|c|c|c|c|c|c|c|}
\cline { 2 - 7 } \multicolumn{1}{|c|}{} & \multicolumn{2}{c|}{ Hombres } & \multicolumn{2}{c|}{ Mujeres } & \multicolumn{2}{c|}{ Total } \\
\hline Grupos & Número & Porcentaje & Número & Porcentaje & Número & Porcenaje \\
\hline 1 & 7 & $21,21 \%$ & 9 & $27,27 \%$ & 16 & $48,48 \%$ \\
\hline 2 & 10 & $30,30 \%$ & 7 & $21,21 \%$ & 17 & $51,52 \%$ \\
\hline Total & 17 & $51,52 \%$ & 16 & $48,48 \%$ & 33 & $100 \%$ \\
\hline
\end{tabular}

Fuente: Elaboración propia.

Antes de la discusión grupal se les aplicó un breve cuestionario, con dos objetivos. En primer lugar, que se familiarizaran con el tema de discusión, pues solo se les había anunciado el título "la música", para entrar a hablar del asunto ya centrados en el mismo. En segundo lugar, con objeto de obtener información de su opinión, en este caso, de carácter individual, para así tener un insumo diferente al obtenido de la realización y participación en el propio grupo. Por otra parte, y si bien no es objeto de este estudio, se debe mencionar que esta técnica de investigación social aplicada suele agradar a las personas convocadas -en este caso en particular además por el tema tratado- y más allá de ello, funciona como un cohesionador de grupos, lo cual es favorable al compartir, expresar y desarrollar una reflexión individual y colectiva sobre el tema que se aborda, pues se trató de grupos escolares de los mismos salones y materias en su día a día. 


\section{El gusto por la música y su por qué ${ }^{2}$}

La primera pregunta del cuestionario escrito, la que iniciaba la participación oral en el grupo fue si gustaba la música y por qué. La segunda, interrogaba sobre para qué servía la música, es decir, para qué les servía a ellos/as. Todas las personas participantes en estos ejercicios respondieron de manera afirmativa a la pregunta inicial cuantitativa y cerrada. En cuanto a su acompañante cualitativa y abierta, del por qué, se recibió una amplia gama de explicaciones, tales como: que distrae y alegra; es un refugio y una inyección contra el estrés; un desahogo emocional y, además -cuando todavía no se había hablado para nada de emociones- algunas intervenciones o respuestas iban en el sentido de que servía para animarse cuando se sentían enojados o estaban tristes. En general, la mayoría de las narraciones y participaciones sobre el porqué iban en el sentido de la emoción, su sentir o su expresión, siempre y en todo momento se trataba, directamente, de emociones o sensaciones corporales, tales como el estrés o, mejor dicho, su contrario, la relajación, la cual también tiene relación con una emoción, en este caso particular, la angustia.

Por otro lado, indican que les ayuda a pensar y a ser creativos. Además, les hace sentir bien y, por lo tanto, les beneficia y les gusta. Esas respuestas sobre por qué se reiteraron con la siguiente pregunta, sobre para qué sirve la música. Algunas se relacionan, también, con los interrogantes concretos y directos sobre las emociones que más adelante se presentarán. Sin embargo, es necesario reiterar y destacar que antes de preguntar sobre alguna emoción, las respuestas generales en torno a la música, su gusto y su función, abrieron la puerta de par en par a la expresión emocional. Vamos, a continuación, a ir desgranando y exponiendo, al tiempo que analizamos e interpretamos, en la medida de lo posible, la información obtenida a través de los cuestionarios y grupos focales de esta investigación.

Para empezar, sobre el porqué nos gusta la música es importante decir que se trata de la repercusión que esta causa en el cerebro. Justamente, como se demostró en la investigación y en las reacciones emocionales que su recepción conlleva. Según Valorie Salimpoor, del Instituto Neurológico de Montreal de la Universidad de McGill, menciona que es como una recompensa intelectual, algo así como que al escucharla se provoca una gran actividad neurológica que involucra varias partes del cerebro (Salimpoor citado Ball, 2014). Esta actividad va desde el núcleo de accumbens, neuronas del encéfalo pasando por el área sensorial, la ejecutiva y la emocional, además del córtex, todas ellas se ven implicadas fisiológicamente hablando. La música gusta por las expectativas que genera en la mente; recuerda hechos del pasado a través de la memoria; revive experiencias

2 En los diferentes apartados se combina teoría, estudios previos y resultados empíricos con objeto de complementarse hasta donde ello sea posible. 
y emociones; potencia la imaginación, la creatividad y, básicamente, como se ha dicho, crea cierto juego de expectativas.

Por otra parte, son varios los estudios que muestran la similitud entre la reacción químico-eléctrica cerebral que proporciona la música preferida con la reacción a las drogas psicodélicas, el deleite del plato de comida que más gusta o el buen sexo. Eso sí, las preferencias se basan, al parecer, más que en la biología, en la cultura: a lo que se haya acostumbrado el cerebro. Es decir, a lo que ha escuchado desde el feto hasta los primeros años de vida y el resto de su existencia. Es que "nuestras preferencias acústicas dependen más de la exposición a un determinado estilo musical que de un rasgo inherente al sistema auditivo" (Barajas, 2016). Robert Zatorre (citado por Manes, 2015) afirma que:

una vez que los sonidos impactan en el oído, se transmiten al tronco cerebral y de ahí a la corteza auditiva primaria; estos impulsos viajan a redes distribuidas del cerebro importantes para la percepción musical, pero también para el almacenamiento de la música ya escuchada; la respuesta cerebral a los sonidos está condicionada por lo que se ha escuchado anteriormente, dado que el cerebro tiene una base de datos almacenada y proporciona todas las melodías conocidas (párr. 1).

Una de las hipótesis que surge a partir de esto es lo mencionado sobre el gusto musical, en el sentido de que el cerebro, constantemente, desea anticipar lo que va a pasar:

existen circuitos en la corteza cerebral involucrados en la percepción, codificación, almacenamiento y en la construcción de los esquemas abstractos que representan las regularidades extraídas de nuestras experiencias musicales previas. La construcción de expectativas y su posible violación son clave para una respuesta emocional (Ibáñez y Amoruso citado por Manes, 2015, párr.1).

En resumen, la música o "musicofilia" según el concepto de Sacks (2015) no solo nos afecta en carácter y el enorme poder que posee sobre las personas, sino que hay una propensión o afinidad fundamental en todas las culturas hacia la música. La construimos en la mente, a partir del cerebro, desde la apreciación estructural del inconsciente y deviene en reacción emocional y motora -en el sentido de percepciones musculares-. La música actúa sobre el sistema nervioso y sus funciones vitales (Jankélevitch, 2005).

Pasemos a retomar los resultados de la investigación sobre el tema en el estudio de caso, según las expresiones recabadas de los participantes. Preguntar por qué es indagar la razón, causa o motivo; esto es, el origen y la explicación. Aquí, como en los subsecuentes apartados, se revisan las dimensiones musico-emotivas a través de las expresiones semántico-discursivas. A continuación, se presentan unos cuadros elaborados según campos semánticos. En primer lugar, es posible afirmar que el campo de "regulación" sería el macrocampo al 
incluir lo emocional, cognitivo y comportamental (Cuadro 4). En segundo lugar, como tendencia semántica cuantitativa, el aspecto emocional aparece como el más numeroso, por lo tanto, más importante a la hora de explicar el porqué del gusto por la música.

Tabla 4. Macrocampo y campos semánticos

\begin{tabular}{|c|c|c|}
\hline \multicolumn{3}{|c|}{ Regulación } \\
\hline Emocional & Cognitiva & Comportamental \\
\hline
\end{tabular}

Fuente: Elaboración propia con base en cuestionarios de grupos focales.

La palabra "regulación" surgió del análisis e interpretación semántica en torno a los vocablos y frases recogidas, a modo de testimonios, de las personas participantes en los grupos focales. Como respuesta a la pregunta de por qué el gusto por la música, no siempre se obtuvo el término "regulación", también estuvo el vocablo "equilibrio", también ante el para qué servía la música en sus vidas cotidianas. Tanto palabras como frases iban, en general, en dicho sentido.

Es necesario mencionar que las narraciones se presentaron como respuestas en los cuestionarios aplicados, antes del grupo de enfoque. Si bien este nos permite contabilizar y señalar campos semánticos con tendencias numéricas. Mucho más que los testimonios orales recabados como participación en los grupos, los cuales nos sirven más para ilustrar, profundizar y ampliar, cualitativamente, algunas opiniones o puntos de vista que a continuación también se expondrán.

Con base en el cuestionario se analizan las unidades fraseológicas y se eligen ciertos vocablos por su frecuencia y su relación asociativa de significado. en relación con las respuestas abordadas. Con las palabras seleccionadas se organizan en subcampos semánticos según la frecuencia de aparición, como ya se mencionó. Un campo lo denominamos "regulación emocional", ya que se trata de emociones.

Si bien hay algunas emociones mencionadas, tales como, "alegría" o "felicidad", o la sensación emocional de "sentirse bien", se presentan otras expresiones que van el en sentido de la regulación, ya sea para "reducir la intensidad" de la emoción o para "incrementarla". Además de la intensidad, en el sentido de que se relaja o se anima, está el cambio de emoción de insatisfactoria a satisfactoria, a través de la modulación emocional. Para un caso, al pasar de la angustia a la relajación, del estrés al desestrés, en el caso de bajar la intensidad. Para el otro caso, el subirla sería pasar de aburrirse a divertirse, del desánimo al ánimo, es decir, de lo desagradable a lo agradable. Por ejemplo, para lo primero, se señala por qué les gusta la música y es que les "relaja" y "desestresa", les provoca "tranquilidad". 
En la segunda dirección, está el gusto, porque la música "divierte", "distrae", "entretiene". Todo ello tiene que ver con elevar la intensidad, lo mismo que "anima" o "prende".

Como cuestión más general, se aprecia el campo que habla de las emociones y lo que estas les proporcionan, o de cómo se "modifican los estados de ánimo", todo ello producto de la música. Así, el campo "regulación emocional" se subdivide en varios subcampos: "relaja", "divierte", "sentirse bien", "emociones", "modificación de estados de ánimo" y "sensaciones" (Cuadro 5)

Tabla 5. Reguladora emocional (emociones y estados de ánimo)4

\begin{tabular}{|c|c|c|c|c|c|}
\hline $\begin{array}{c}\text { Bajar } \\
\text { intensidad }\end{array}$ & \multicolumn{4}{|c|}{ Emociones } & $\begin{array}{c}\text { Elevar } \\
\text { intensidad }\end{array}$ \\
\hline Relaja 26 & $\begin{array}{c}\text { Sentirse bien } \\
18\end{array}$ & Emociones: & $\begin{array}{c}\text { Modifica } \\
\text { estados } \\
\text { de ánimo 3 }\end{array}$ & Sensaciones & Divierte 22 \\
\hline Tranquiliza & Chida & Provoca & Alegría 3 & $\begin{array}{c}\text { Estimula } \\
\text { sentidos }\end{array}$ & Distrae \\
\hline Desestresa & Da placer & Estimula & Felicidad 2 & $\begin{array}{c}\text { Experiencia } \\
\text { estética }\end{array}$ & Desaburre* \\
\hline Paz & Vida & Transmite & & & Entretiene \\
\hline & Vital & & & & Anima 3 \\
\hline & Sentir viva & & & & Prende 3 \\
\hline
\end{tabular}

Fuente: Elaboración propia con base en cuestionarios de grupos focales.

En cuanto al campo de "regulación cognitiva", así denominado debido a que las expresiones son "ayuda a estudiar", "ayuda a concentrarse", "estimula el aprendizaje". Así, la música tiene lugar en menor medida, al parecer, y según las pocas expresiones recabadas en este sentido (Cuadro 6).

3 En este y los siguientes cuadros se proporciona el número de personas que dieron dicha respuesta.

4 *Dicha palabra, como tal, no existe, no obstante, como varias personas así se expresaron se optó por mantenerla en su versión original.

ESCENA. Revista de las artes, 2019, Vol. 79, Núm. 1 (julio-diciembre), pp. 25-58 
Tabla 6. Reguladora cognitiva

\begin{tabular}{|c|c|}
\hline Ayuda a pensar & Ayuda a estudiar \\
\hline Inspirarme 4 & Aprendizaje \\
\hline & Concentrarse 3 \\
\hline
\end{tabular}

Fuente: Elaboración propia con base en cuestionarios de grupos focales.

Otra cosa es la regulación comportamental, en cuanto a que la música "anima a hacer cosas". En mayor número se dice que es porque se "expresa", "desahoga" y "libera" (Cuadro 7). Este último se reitera y enlaza con la dimensión emocional, por supuesto.

Tabla 7. Reguladora comportamental

\begin{tabular}{|c|c|c|}
\hline Inspira a hacer las cosas & Expresar & Expresión artística \\
\hline Anima a hacer las cosas 3 & Desahogar & \\
\hline & Liberar 2 & \\
\hline
\end{tabular}

Fuente: Elaboración propia sobre cuestionarios de grupos focales.

Con objeto de ampliar esta información se presentan frases literales transcritas de las y los jóvenes que participaron en los ejercicios, ya sea en las respuestas del cuestionario, o que se trate de su expresión oral durante el proceso del grupo. La música gusta "porque en ella me puedo tranquilizar, pienso, me inspira hacer algo"; "es una de las artes más bonitas de todas y sirve para poder expresar muchas cosas"; "es divertida"; "me relaja"; "porque es bonita y genera felicidad", esto según algunas expresiones en Secundaria. Por su parte, las chicas y chicos de $\mathrm{CCH}$ dicen que "es una forma de relajarme", "me hace sentir bien", "porque me causa sentimientos chidos y me causa placer", "porque es lo único que modifica mi ánimo en segundos", "es una forma de expresión y también me relaja mucho", "porque me desestresa". El gusto por la música según estas personas de educación media y media-superior apunta a que les "inspira" o les "desahoga".

En cuanto a los universitarios, señalan que les gusta la música "porque es un distractor en los momentos de tensión o aburrimiento", "experiencia estética, supongo que a todos les gusta, la diversión, relajación y aprendizaje", "es la expresión artística más sincera creada por el hombre", "estimula los sentidos, ayuda a estudiar", "algo que me relaja mucho y me hace pensar en muchas cosas", "es una fuente de muchas sensaciones, en su mayoría placenteras". En fin, "es algo vital para una persona", "me hace sentir viva y 
expresa sentimientos que a veces no decimos". Un joven de educación superior afirmó que "es una expresión artística que gusta porque sirve para dar algún punto de vista o expresar un malestar y desahogarte". Otro más dijo gustarle porque "le enajena", lo cual explica: "me gusta mucho la música clásica o la instrumental, yo la ocupo cuando voy en el transporte público porque es muy salvaje para mí ese escenario, entonces me enajena de ello y me proyecta a algo utópico, a una situación distinta de la que hay". Dijo un chico "es una medicina para el alma".

Parece que el sentirse bien, relajarse y divertirse son las causas explicativas mayoritarias de por qué gusta la música a la juventud consultada. Estas coinciden como parte de las repercusiones cerebrales de las que se habló con anterioridad en este trabajo. Así, a la música la consideran "parte de nuestra vida, desde el nacimiento, los primeros sonidos, el embarazo y nos sirve para relajación, para alimentarnos", expresa en el grupo una joven universitaria. Justamente, para qué sirve la música es el próximo punto que se aborda en estas páginas. En por qué gusta ya se ha respondido de forma indirecta a este interrogante, pues como se verá, a continuación, la dirección de las respuestas en los campos y subcampos semánticos se traslapan.

\section{Para qué sirve la música}

A diferencia de por qué, el para qué, se relaciona con el fin u objetivo; la función, la comprensión que diría Morin (1999) al separar explicación de comprensión, si bien ambas son importantes en la investigación. En cuanto a este punto sobre el para qué, se afirma que: "la función de la música es la socialización", según Jeremy Montagu de la Universidad de Oxford (citado por Oliveira, 2017), ya que lo primero que escucha un bebé es el tarareo de su madre para calmarlo y, seguramente, nuestros ancestros y las madres de estos acunaban a sus hijos con ciertos sonidos musicales. Se trata de "la hipótesis de que la música tuvo una función esencial en la formación y supervivencia de grupos y en la mitigación de conflictos" (Oliveira, 2017, párr. 1). De hecho, Mark Tramo, del Instituto para la Música y la Ciencia del Cerebro de la Universidad de Harvard, mencionado también por Oliveira, apoya dicho enfoque, señalándo que la música fue un factor de cohesión social de primer orden, en el sentido de que los hombres precisaban organizarse con objeto de cazar, defenderse y sobrevivir. La música sirve, pues, para comunicarse y para compartir emociones. Esto último hizo que sobreviviera cuando apareció el lenguaje a través del desarrollo lingüístico. En fin, que la música reúne y une a la gente, algo similar a las emociones que siempre están en relación. Se comparten emociones a través de la música, se canta y se baila colectivamente, las personas se mueven al unísono (Oliveira, 2017). 
También se señala su componente funcional-emocional en tanto "sentirse bien", por lo ya dicho sobre su actuación cerebral similar al sexo, las drogas o la comida placentera. Activan el lóbulo central y producen dopamina actuando sobre el cerebelo que, al sincronizarse al ritmo de la música, produce placer, de acuerdo con Daniel Levin (citado por Oliveira, 2017). Estar bien, disfrutar, sentir placer, nutrirse de afectos, tiempos y espacios gozosos, a todo ello nos invita la música o cierto tipo de música, por una parte, según su armonía, por otra, según también los gustos musicales. Además, estimula la creatividad, intensifica la capacidad de procesamiento abstracto, agiliza la mente y la búsqueda de soluciones ante las dificultades de todo tipo. En el caso de la infancia esto está bastante estudiando: como la música acrecienta las capacidades motoras y cognitivas, por ejemplo.

El ámbito de la terapia, en general, ha ganado terrero tanto en el espacio psicológico y mental como en el de las enfermedades físicas. Varias de estas pueden curarse o mejorar a través de canciones, como apunta Oliver Sacks (2015). Es más, Jourdain (2008) afirma que la música calma o vence a los síntomas, porque relaja el flujo cerebral, hace que nos desestructuremos, en el sentido de percibir viejos programas que repetimos en la conducta o hábitos mentales congelados, que reiteramos una y otra vez. También disminuye el dolor y produce endorfinas, lo cual es del todo positivo para varias dolencias, especialmente, las crónicas. La musicoterapia es también reconocida e importante (Waisburd \& Erdmenger, 2007; Muñoz, 2008). Esta busca activar los procesos fisiológicos y emocionales; varios trastornos cerebrales pueden ser aliviados con ella, al estimularse las conexiones involucradas en la emoción, la recompensa, la cognición, la sensación y el movimiento (Manes, 2015), como parte de la neuroplasticidad del cerebro. También se dice que, al involucrar el movimiento del cuerpo, el ejercicio físico puede mejorar la circulación, proteger el cerebro y facilitar la función motora. Sobre todo, incide en las emociones, sensaciones y estados anímicos, al aumentar el ánimo o, a la inversa, por lo que puede ser empleado en rehabilitación y adaptarse a las necesidades de cada trastorno y de cada persona en concreto. De hecho, la educación musical, como la educación emocional (De la Torre, 2012) contribuyen a disminuir la depresión, la angustia y el estrés generalizado en el que vive buena parte de la sociedad contemporánea.

A continuación, se presenta la perspectiva y opinión juvenil de para qué sirve la música en sus vidas. Nuevamente, se trabajaron los campos semánticos como en el anterior apartado. Es curioso como aquí, en uno de los relatos en torno al para qué sirve la música, se mencionó de forma directa "para armonizar" y se la consideró "una forma terapéutica", al aparecer también la palabra "regular" y el vocablo "equilibrar". La función de "relajar" domina cuantitativamente al crear el subcampo más numeroso, que incluye "tranquilizar" y "desestresar", considerados muy similares o cuasi sinónimos para el caso que nos ocupa, en el sentido de "disminuir la intensidad". En segundo lugar, se encuentra el "desaburrirse" y "disfrutar", "entretenerse" y "divertirse", en fin, "pasarla bien", en este caso, en el sentido de 
"aumentar la intensidad". Sin olvidar mencionar "sentirse bien" o, incluso, algunas emociones, tales como, "alegría", "felicidad" o "tristeza" (Cuadro 8). Lo dicho para el porqué gusta, sobre el paralelismo entre la intensidad de una emoción desagradable e insatisfactoria que se pasa a una agradable y satisfactoria también aplica en este caso. Esto es, además de la intensidad, está la transformación emocional de una, que se podría llamar negativa y que daña, a una positiva y que hace bien a la persona.

Tabla 8. Reguladora emocional (emociones y estados de ánimo)

\begin{tabular}{|c|c|c|c|c|c|}
\hline $\begin{array}{c}\text { Bajar } \\
\text { intesidad }\end{array}$ & \multicolumn{4}{c|}{ Emociones } & $\begin{array}{c}\text { Elevar } \\
\text { intensidad }\end{array}$ \\
\hline Relaja 46 & $\begin{array}{c}\text { Sentirse } \\
\text { bien 3 }\end{array}$ & $\begin{array}{c}\text { Cambiar } \\
\text { el ánimo }\end{array}$ & $\begin{array}{c}\text { Sentir } \\
\text { sentimientos }\end{array}$ & Sanar & $\begin{array}{c}\text { Desaburrirme } \\
29\end{array}$ \\
\hline Tranquiliza & Sentir la vida & Cataliza & Alegría & Terapéutica & Disfrutar \\
\hline Desestresa & Estar bien & Regula & Reír 5 & Ayuda & Entretenerme \\
\hline & & Armoniza & Felicidad 5 & Acompaña & Pasarla bien \\
\hline & & Equilibra & Tristeza & & Divertir \\
\hline & & & Llorar 6 & & Animarme 3 \\
\hline
\end{tabular}

Fuente: Elaboración propia con base en cuestionarios de grupos focales.

Como aspectos cognitivos destacan la "reflexión" y la "concentración". Lo primero, como "inspiración", "introspección" o, incluso, el "cambio de la forma de pensar". Lo segundo, relacionado con "aprender", "conocer", "analizar" y "comprender", relacionado con la tarea como estudiantes que son (Cuadro 9).

Tabla 9. Reguladora cognitiva

\begin{tabular}{|c|c|l|l|l|}
\hline Reflexionar & $\begin{array}{c}\text { Concentrarme } \\
\text { en la tarea }\end{array}$ & Recordar 1 & Olvidar 1 & Identificarme 3 \\
\hline Inspirarme & Aprender & & & \\
\hline Cambiar & Conocer, & & & \\
\hline $\begin{array}{c}\text { Manera de } \\
\text { pensar, }\end{array}$ & Analizar & & & \\
\hline $\begin{array}{c}\text { Adentrarse } \\
\text { en uno 9 }\end{array}$ & Comprender 9 & & & \\
\hline
\end{tabular}

Fuente: Elaboración propia con base en cuestionarios de grupos focales.

ESCENA. Revista de las artes, 2019, Vol. 79, Núm. 1 (julio-diciembre), pp. 25-58 
Como asuntos comportamentales, el "expresar" ideas y emociones, o bien, "desahogarse". Además de las actividades que comporta e implica la música: "cantar", "escuchar" y "bailar", propias de su disfrute y como parte de la acción y el movimiento musical (Cuadro 10).

Tabla 10. Reguladora comportamental

\begin{tabular}{|c|c|c|c|}
\hline Hacer actividades & Socializar 5 & Expresar & Actividades \\
\hline $\begin{array}{c}\text { Hacer mejor } \\
\text { las cosas 4 }\end{array}$ & & Desahogarme & Escucharla \\
\hline & & Expresar ideas & Cantarla \\
\hline & & Expresar emociones & Bailarla 14 \\
\hline & & Sentimientos 17 & \\
\hline
\end{tabular}

Fuente: Elaboración propia con base en cuestionarios de grupos focales.

Las oraciones que explican el para qué sirve la música entre los jóvenes de secundaria señalan, entre otras cosas: "para relajarme, concentrarme, para el trabajo y para disfrutarla"; "identificarme, poder cambiar tu manera de pensar o simplemente para hacerte pasar un buen rato"; "para relajarme y alegrarme"; "para relajarme y llorar"; "para acabar rápido mis tareas"; "para escucharla cuando estoy triste, feliz o cualquier situación sentimental". En un grupo, un chico dijo "como que me desestresa" y "me distrae"; otro mencionó: "para no aburrirme cuando me ponen a hacer quehacer"; otro más expuso: "es una forma de expresión, o sea, al menos para mí es como cuando no puedes expresarte así con palabras". "Desestresarme y desaburrirme" fueron las palabras más nombradas en los grupos, por parte de este nivel educativo. Además, afirman que "me hace sentir alegre" o "me hace sentir bien" y "socializar y conocer a más personas en las fiestas". Así que, como se dijo en las primeras frases de este apartado, la música sirve para socialización y para sentirse bien, la juventud consultada así lo corrobora. En el CCH apuntaron que "para pasar el rato"; "concentrarme y relajarme"; "desestresarme y ponerme feliz"; "para tranquilizarme y cambiar el ánimo"; "tranquilizarnos y ayudar a identificar nuestros sentimientos".

Entre los dos primeros niveles educativos destaca el que "entretiene" a veces y "tranquiliza" otras. Además de que "puede servir como un apoyo para estudiar o hacer alguna actividad". Por ejemplo, una niña de secundaria expresa en el grupo de discusión "a mí me sirve mientras me pongo a leer, ya que me sirve para imaginarme un paisaje, ambientarme, me sirve para tranquilizarme o hacer mis actividades". Otro chico de este nivel afirma que le 
sirve porque "puedes expresar muchas cosas, te puedes dar a conocer a ti mismo, puedes hacer muchas cosas a través de ella". Añade una joven de CCH entre las actividades "meditación y relajación". Además, testimonia un adolescente de secundaria: "te puede volver más creativo, ayudar a mejorar tu vocabulario, que explores las barreras de tu pensamiento, o sea puedes reflejar mucho tu personalidad por medio de una canción". Como se observa, son expresiones relacionadas con las emociones, la mente y la conducta.

Entre los universitarios sirve para "relajarme y disfrutar los momentos así como los recuerdos"; "reflexionar, bailar, reír, relajar"; "es una forma de socializar, buscar a personas afines a gustos y una forma hasta terapéutica dependiendo de la situación"; "para bailar, expresarnos, consolarnos, relajarnos, depende del ritmo"; "en lo personal para entretenerme, relajarme, motivarme"; "deleitar nuestros oídos al momento que nos enfocamos en diversas situaciones"; "ayuda a expresar ideas, sentimientos, también para relajar"; "para crear conciencia de mi vida, reflexionar, distraerme, desahogarme". En este nivel educativo una chica dijo en el grupo indicó que "sirve para distraerme, la ocupo como pasatiempo, bueno, realmente es puro hobby, creo". Mientras otra añadió "pues a mí realmente me sirve para sentirme feliz, creo que la música hace que expresemos las emociones que a veces no podemos decir, nos sentimos como felices y a la vez libres". Otra más afirmó "a mí me sirve en mis actividades, yo no puedo hacer algo si no escucho música o algo de fondo, porque me tensa... me ayuda mucho la música que tenga algún mensaje, que no sea monótono, por ejemplo, el sonido, porque cuando es el mismo también llega a tensarte, la ocupo como para distraerme, para sentirme armonizada". Varias fueron las expresiones que señalaron "me ayuda en mis tareas diarias", como una suerte de acompañamiento en la cotidianeidad, en cuestiones escolares y en todo tipo de actividades.

La música puede cambiar incluso la vida, como apunta una chica universitaria al expresar en el grupo lo siguiente: "pues en mi vida ha dejado una gran huella, la verdad que nunca pensé estar en un conjunto con un arreglo sinfónico y tocar en la Ollin Yoliztli, fue para mí un sueño, te hace pensar y analizar cómo trasciende en tu vida. A mí me ayudó a ser mejor persona, a ser más organizada, a formar hábitos...creo que lo más bonito me ha pasado con la música". Otro joven del mismo grupo, en el mismo sentido, asentó: "yo creo que a mí me sirvió para empezar a definir mi personalidad. Ahora me sirve como un instrumento, para tratar de apoyarme con la música para estar regularmente contento, oyendo lo que me gusta. Me ayuda a recordar, bueno o malo, es parte de mi vida. A pesar que no estoy todo el tiempo oyéndola, en mi vida significa algo importante". Mientras una mujer de este grupo señala que: "yo creo que ha sido como mi compañerita desde chiquita, a mí me gusta mucho bailar, entonces como que la música siempre ha estado conmigo, siempre ha ido cambiando, no define mi personalidad porque no tengo un género en específico, me gusta todo". Otro muchacho de un grupo diferente añade: "para mí fue una llave, pues 
tengo amigos gracias a ella, abrió relaciones". Por su parte, una muchacha del mismo grupo expresó: "en mi caso creo que me trajo donde estoy ahorita. Cuando tenía 8 o 9 años escuché una canción de Rock \& Roll mexicano llamada Tlatelolco, cuando escuché esa canción al inicio solo la repetía, pero después hizo que construyera un lazo fuerte con mi papá porque yo le pregunté qué significaba lo que estaba cantando y comenzó a platicarme a grandes rasgos la matanza de Tlatelolco. Eso me hizo investigar más, después leer el libro de La noche de Tlatelolco de Elena Poniatowska. Esa canción ha sido una marca para mí porque por ese hecho decidí estudiar política".

La música es importante para equilibrar emociones, sin embargo, algunas opiniones se vertieron también en el tono de: ejercer un control de tipo dominador mayor. Hay estudios que comprueban que de cierta manera, en algunos lugares tener música de fondo tiene la función de bajar un poco los niveles de energía de las personas (Sacks, 2015). La música anima y desanima "mueve energía" -como se afirmó en varias intervenciones-, por tanto, es susceptible a ser utilizada intencionalmente para ello. Es que la música sirve "para muchas cosas", como "para imaginar, para pensar, para tranquilizar", señaló un hombre universitario. Finalmente, un muchacho dijo "sanar las heridas y enaltecer el espíritu". Claramente, como se está viendo a lo largo de estas páginas, la población consultada considera, de forma mayoritaria, que la música sirve para "equilibrar las emociones de un individuo, depende de la situación en qué se encuentre" (joven universitario, 2017). Mientras una chica en el grupo del mismo nivel educativo afirma en sentido similar:

es como un catalizador de emociones, no sé, si te sientes triste escuchas una tonada triste o música triste, lo que va a hacer es que te sientas más triste, y si escuchas en lugar de algo triste, algo más alegre, naturalmente te vas a empezar a sentir mejor. Es parte de nosotros y vivemos con ella y va marcando momentos en nuestra vida como emociones y va haciéndolas más grandes o más chicas" (intervención en grupo focal, 2017).

La música socializa, es relajante, se disfruta, ayuda, acompaña. Incluso, es catalizadora, equilibra y armoniza en el sentido terapéutico de los términos, como se muestra en las transcripciones realizadas de los grupos de discusión o en los cuadros resúmenes de las expresiones vertidas en los cuestionarios. Así, los enfoques teóricos sobre el tema y las experiencias juveniles parecen coincidir y complementarse. El hecho es que en los testimonios del grupo de discusión reconocieron que "a las personas les sirve de diferente manera, a unos les tranquiliza, a algunos los extasía y a algunos les molesta, dependiendo de los ritmos que se pudieran estar escuchando" (joven universitaria, 2017). Justamente, tal y como veremos en el siguiente apartado de este artículo, el cual relaciona directamente emociones y estilos musicales ante la pregunta expresa sobre el asunto. 


\section{Emociones y géneros musicales}

Una batería de interrogantes, del cuestionario aplicado antes de la discusión, giraba en torno a qué estilos musicales les producía qué emociones. O sea, se preguntaba sobre, por ejemplo, ¿qué tipo de música te tranquiliza y da paz? Seguía: ¿cuál te produce alegría, enojo, tristeza, energiza y te quita la energía? Se trata de preguntas cualitativas abiertas. Por lo tanto, las respuestas se cerraron con posterioridad para ser cuantificadas y encontrar posibles tendencias que, como se verá, sí las hay. La contestación es directamente el estilo musical que les provoca dichas emociones o estados de ánimo. A continuación, se presentan unos cuadros resumen para analizar por sexo, grado y nivel educativo -y por extensión la edad-, con objeto de mostrar información fina y detallada del asunto. 
Tabla 11. ¿Qué tipo de música te tranquiliza y te da paz?

\begin{tabular}{|c|c|c|c|c|c|c|c|c|c|c|c|c|c|c|c|}
\hline \multirow[b]{2}{*}{ Género musical } & \multicolumn{3}{|c|}{ Secundaria } & \multicolumn{3}{|c|}{ Bachillerato } & \multicolumn{3}{|c|}{ Universidad } & \multicolumn{2}{|c|}{ Hombres } & \multicolumn{2}{|c|}{ Mujeres } & \multicolumn{2}{|c|}{ Total } \\
\hline & Hombres & Mujeres & Total & Hombres & Mujeres & Total & Hombres & Mujeres & Total & Número & Porcentaje & Número & Porcentaje & Número & Porcentaje \\
\hline Baladas/Trova & - & - & - & - & 1 & 1 & 2 & 3 & 5 & 2 & $4,44 \%$ & 4 & $10,81 \%$ & 6 & $7,32 \%$ \\
\hline Banda & 1 & - & 1 & - & 1 & 1 & - & - & - & 1 & $2,22 \%$ & 1 & $2,70 \%$ & 2 & $2,44 \%$ \\
\hline Blues & - & - & - & - & 1 & 1 & - & - & - & - & - & 1 & $2,70 \%$ & 1 & $1,22 \%$ \\
\hline Clásica/Ópera & 3 & 4 & 7 & 6 & 2 & 8 & 3 & 4 & 7 & 12 & $26,67 \%$ & 10 & $27,03 \%$ & 22 & $26,83 \%$ \\
\hline $\begin{array}{l}\text { Electrónica/Techno/Psycho/ } \\
\text { Deep House/Trance }\end{array}$ & - & 2 & 2 & 2 & 1 & 3 & 3 & - & 3 & 5 & $11,11 \%$ & 3 & $8,11 \%$ & 8 & $9,76 \%$ \\
\hline Folclore & 1 & - & 1 & - & - & - & - & - & - & 1 & $2,22 \%$ & - & - & 1 & $1,22 \%$ \\
\hline Instrumental & - & 1 & 1 & - & - & - & 1 & - & 1 & 1 & $2,22 \%$ & 1 & $2,70 \%$ & 2 & $2,44 \%$ \\
\hline Jazz & 2 & 1 & 3 & 2 & 1 & 3 & 2 & 2 & 4 & 6 & $13,33 \%$ & 4 & $10,81 \%$ & 10 & $12,20 \%$ \\
\hline Pop & 1 & 3 & 4 & 1 & - & 1 & - & 1 & 1 & 2 & $4,44 \%$ & 4 & $10,81 \%$ & 6 & $7,32 \%$ \\
\hline Rap & 4 & 1 & 5 & - & - & - & 2 & - & 2 & 6 & $13,33 \%$ & 1 & $2,70 \%$ & 7 & $8,54 \%$ \\
\hline Reggae & - & - & - & 1 & - & 1 & 2 & - & 2 & 3 & $6,67 \%$ & - & - & 3 & $3,66 \%$ \\
\hline Reggaeton & - & 1 & 1 & - & 1 & 1 & - & - & - & - & - & 2 & $5,41 \%$ & 2 & $2,44 \%$ \\
\hline Rock/Indie/Rock clásico & 1 & 1 & 2 & 2 & 4 & 6 & 2 & - & 2 & 5 & $11,11 \%$ & 5 & $13,51 \%$ & 10 & $12,20 \%$ \\
\hline Tango & - & - & - & 1 & - & 1 & - & - & - & 1 & $2,22 \%$ & - & - & 1 & $1,22 \%$ \\
\hline Ninguna & - & - & - & - & 1 & 1 & - & - & - & - & - & 1 & $2,70 \%$ & 1 & $1,22 \%$ \\
\hline Total & 13 & 14 & 27 & 15 & 13 & 28 & 17 & 10 & 27 & 45 & $100 \%$ & 37 & $100 \%$ & 82 & $100 \%$ \\
\hline
\end{tabular}

Fuente: Elaboración propia con base en cuestionarios de grupos focales.

En cuanto al estilo musical que parece darles tranquilidad y paz (Cuadro 11) , en primer lugar, está la música clásica y ópera (26,83\%). En segundo lugar, y a bastante distancia del primero, se en-

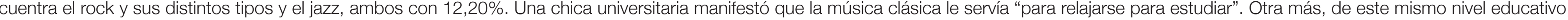

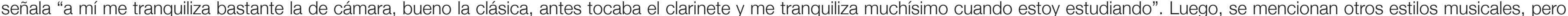

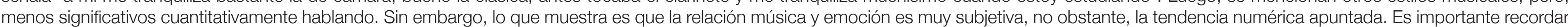
que en el por qué gusta la música y en el para qué sirve el hecho que tranquiliza y relaja fue muy importante. 
Tabla 12. ¿Qué tipo de música te produce alegría?

\begin{tabular}{|c|c|c|c|c|c|c|c|c|c|c|c|c|c|c|c|}
\hline \multirow[b]{2}{*}{ Género musical } & \multicolumn{3}{|c|}{ Secundaria } & \multicolumn{3}{|c|}{ Bachillerato } & \multicolumn{3}{|c|}{ Universidad } & \multicolumn{2}{|c|}{ Hombres } & \multicolumn{2}{|c|}{ Mujeres } & \multicolumn{2}{|c|}{ Total } \\
\hline & Hombres & Mujeres & Total & Hombres & Mujeres & Total & Hombres & Mujeres & Total & Número & Porcentaje & Número & Porcentaje & Número & Porcentaje \\
\hline Baladas/De amor & 3 & 2 & 5 & - & - & - & - & - & - & 3 & $6,98 \%$ & 2 & $4,88 \%$ & 5 & $5,95 \%$ \\
\hline Banda & 1 & 1 & 2 & 1 & - & 1 & - & - & - & 2 & $4,65 \%$ & 1 & $2,44 \%$ & 3 & $3,57 \%$ \\
\hline Clásica & - & - & - & - & - & - & 2 & 1 & 3 & 2 & $4,65 \%$ & 1 & $2,44 \%$ & 3 & $3,57 \%$ \\
\hline Electrónica/Techno & 2 & - & 2 & 7 & 2 & 9 & 1 & 1 & 2 & 10 & $23,26 \%$ & 3 & $7,32 \%$ & 13 & $15,48 \%$ \\
\hline Pop & 1 & 6 & 7 & 2 & 4 & 6 & 2 & 4 & 6 & 5 & $11,63 \%$ & 14 & $34,15 \%$ & 19 & $22,62 \%$ \\
\hline Protesta & - & - & - & - & - & - & 1 & - & 1 & 1 & $2,33 \%$ & - & - & 1 & $1,19 \%$ \\
\hline$R \& B$ & - & - & - & - & - & - & 1 & - & 1 & 1 & $2,33 \%$ & - & - & 1 & $1,19 \%$ \\
\hline Rap/Hip-hop & 2 & 2 & 4 & - & - & - & 2 & - & 2 & 4 & $9,30 \%$ & 2 & $4,88 \%$ & 6 & $7,14 \%$ \\
\hline Reggae & - & - & - & 1 & 2 & 3 & 1 & 2 & 3 & 2 & $4,65 \%$ & 4 & $9,76 \%$ & 6 & $7,14 \%$ \\
\hline Reggaeton & 3 & 2 & 5 & - & 1 & 1 & - & - & - & 3 & $6,98 \%$ & 3 & $7,32 \%$ & 6 & $7,14 \%$ \\
\hline Rock/Metal & 2 & 3 & 5 & 3 & 2 & 5 & 3 & 2 & 5 & 8 & $18,60 \%$ & 7 & $17,07 \%$ & 15 & $17,86 \%$ \\
\hline Salsa & - & - & - & - & 1 & 1 & 1 & 3 & 4 & 1 & $2,33 \%$ & 4 & $9,76 \%$ & 5 & $5,95 \%$ \\
\hline Ska & - & - & - & - & - & - & 1 & - & 1 & 1 & $2,33 \%$ & - & - & 1 & $1,19 \%$ \\
\hline Total & 14 & 16 & 30 & 14 & 12 & 26 & 15 & 13 & 28 & 43 & $100 \%$ & 41 & $100 \%$ & 84 & $100 \%$ \\
\hline
\end{tabular}

Fuente: Elaboración propia sobre cuestionarios de grupos focales.

Sobre el género que provoca alegría, en primer lugar, con 22,62\% se encuentra la música pop, seguida con un 17,86\% por el rock/metal. En tercer lugar, la electrónica/techno (Cuadro 12). Una

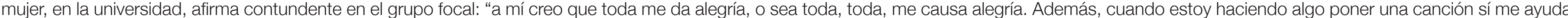
a motivarme a hacer lo que hago". Pero, sí se observa una tendencia hacia tres géneros concretos, por encima de los demás señalados. 
Tabla 13. ¿Qué tipo de música te energiza?

\begin{tabular}{|c|c|c|c|c|c|c|c|c|c|c|c|c|c|c|c|}
\hline \multirow[b]{2}{*}{ Género musical } & \multicolumn{3}{|c|}{ Secundaria } & \multicolumn{3}{|c|}{ Bachillerato } & \multicolumn{3}{|c|}{ Universidad } & \multicolumn{2}{|c|}{ Hombres } & \multicolumn{2}{|c|}{ Mujeres } & \multicolumn{2}{|c|}{ Total } \\
\hline & Hombres & Mujeres & Total & Hombres & Mujeres & Total & Hombres & Mujeres & Total & Número & Porcentaje & Número & Porcentaje & Número & Porcentaje \\
\hline Banda & 1 & - & 1 & - & - & - & - & - & - & 1 & $2,08 \%$ & - & - & 1 & $1,12 \%$ \\
\hline Clásica & - & - & - & - & - & - & 1 & - & 1 & 1 & $2,08 \%$ & - & - & 1 & $1,12 \%$ \\
\hline $\begin{array}{l}\text { Electrónica/Minimal/ } \\
\text { House/Dance/Trance }\end{array}$ & 11 & 5 & 16 & 4 & 6 & 10 & 8 & 9 & 17 & 23 & $47,92 \%$ & 20 & $48,78 \%$ & 43 & $48,31 \%$ \\
\hline Jazz & - & 1 & 1 & - & - & - & - & - & - & - & - & 1 & $2,44 \%$ & 1 & $1,12 \%$ \\
\hline Pop & - & - & - & 1 & 1 & 2 & - & 2 & 2 & 1 & $2,08 \%$ & 3 & $7,32 \%$ & 4 & $4,49 \%$ \\
\hline Rap & 3 & 1 & 4 & 1 & - & 1 & 1 & - & 1 & 5 & $10,42 \%$ & 1 & $2,44 \%$ & 6 & $6,74 \%$ \\
\hline Reggaeton & - & 4 & 4 & 1 & 1 & 2 & 1 & - & 1 & 2 & $4,17 \%$ & 5 & $12,20 \%$ & 7 & $7,87 \%$ \\
\hline $\begin{array}{l}\text { Rock/Metal/Indie/ } \\
\text { Punk Rock/Grunge }\end{array}$ & 1 & 3 & 4 & 4 & 3 & 7 & 6 & 3 & 9 & 11 & $22,92 \%$ & 9 & $21,95 \%$ & 20 & $22,47 \%$ \\
\hline Salsa & - & - & - & - & - & - & - & 1 & 1 & - & - & 1 & $2,44 \%$ & 1 & $1,12 \%$ \\
\hline Ska & - & - & - & 1 & 1 & 2 & - & - & - & 1 & $2,08 \%$ & 1 & $2,44 \%$ & 2 & $2,25 \%$ \\
\hline Trap & 1 & - & 1 & - & - & - & - & - & - & 1 & $2,08 \%$ & - & - & 1 & $1,12 \%$ \\
\hline Urbana & - & - & - & 1 & - & 1 & - & - & - & 1 & $2,08 \%$ & - & - & 1 & $1,12 \%$ \\
\hline Ninguna & - & - & - & 1 & - & 1 & - & - & - & 1 & $2,08 \%$ & - & - & 1 & $1,12 \%$ \\
\hline Total & 17 & 14 & 31 & 14 & 12 & 26 & 17 & 15 & 32 & 48 & $100 \%$ & 41 & $100 \%$ & 89 & $100 \%$ \\
\hline
\end{tabular}

Fuente: Elaboración propia sobre cuestionarios de grupos focales.

Respecto a la música que energiza, casi la mitad de la muestra (48,31\%), una importante cantidad de las personas consultadas coincidieron que es la electrónica/minimal/house/dance/trance, rea-

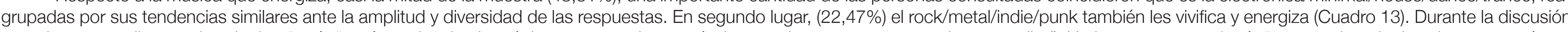

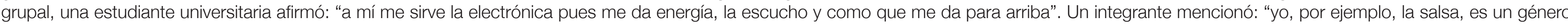

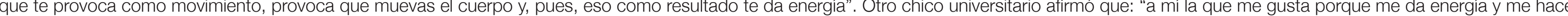

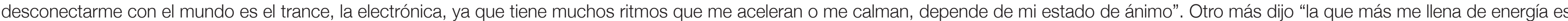
metal". Como se observa en este particular caso, hay una mayoría importante en las tendencias señaladas. 
Tabla 14. ¿Qué tipo de música te enoja?

\begin{tabular}{|c|c|c|c|c|c|c|c|c|c|c|c|c|c|c|c|}
\hline \multirow[b]{2}{*}{ Género musical } & \multicolumn{3}{|c|}{ Secundaria } & \multicolumn{3}{|c|}{ Bachillerato } & \multicolumn{3}{|c|}{ Universidad } & \multicolumn{2}{|c|}{ Hombres } & \multicolumn{2}{|c|}{ Mujeres } & \multicolumn{2}{|c|}{ Total } \\
\hline & Hombres & Mujeres & Total & Hombres & Mujeres & Total & Hombres & Mujeres & Total & Número & Porcentaje & Número & Porcentaje & Número & Porcentaje \\
\hline Banda/Corridos & 2 & 1 & 3 & 2 & 2 & 4 & 2 & 7 & 9 & 6 & $14,29 \%$ & 10 & $23,81 \%$ & 16 & $19,05 \%$ \\
\hline Clásica & - & - & - & - & 1 & 1 & - & - & - & - & - & 1 & $2,38 \%$ & 1 & $1,19 \%$ \\
\hline Cumbia & 1 & 1 & 2 & - & - & - & - & - & - & 1 & $2,38 \%$ & 1 & $2,38 \%$ & 2 & $2,38 \%$ \\
\hline K-pop/Melódica & 1 & - & 1 & - & 1 & 1 & - & - & - & 1 & $2,38 \%$ & 1 & $2,38 \%$ & 2 & $2,38 \%$ \\
\hline Protesta & - & - & - & - & - & - & 1 & - & 1 & 1 & $2,38 \%$ & - & - & 1 & $1,19 \%$ \\
\hline Rap & - & 1 & 1 & 1 & - & 1 & 1 & - & 1 & 2 & $4,76 \%$ & 1 & $2,38 \%$ & 3 & $3,57 \%$ \\
\hline Reggaeton & 8 & 3 & 11 & 5 & 2 & 7 & 3 & 1 & 4 & 16 & $38,10 \%$ & 6 & $14,29 \%$ & 22 & $26,19 \%$ \\
\hline Rock/Metal & 1 & 3 & 4 & 4 & 3 & 7 & 2 & 3 & 5 & 7 & $16,67 \%$ & 9 & $21,43 \%$ & 16 & $19,05 \%$ \\
\hline Ninguna & 2 & 8 & 10 & 2 & 2 & 4 & 4 & 3 & 7 & 8 & $19,05 \%$ & 13 & $30,95 \%$ & 21 & $25,00 \%$ \\
\hline Total & 15 & 17 & 32 & 14 & 11 & 25 & 13 & 14 & 27 & 42 & $100 \%$ & 42 & $100 \%$ & 84 & $100 \%$ \\
\hline
\end{tabular}

Fuente: Elaboración propia con base en cuestionarios de grupos focales.

La música que enoja (Cuadro 14), con 26,19\%, de las personas consultadas es el reggaeton. Esto es así, según lo explicado en las intervenciones de los grupos focales por las letras, el machismo,

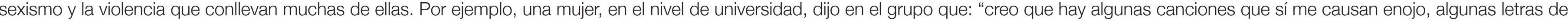

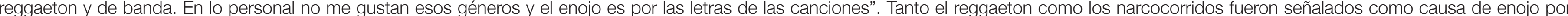

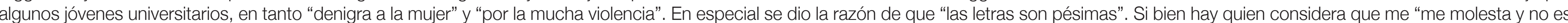
de mi agrado el rock pesado, no lo considero música, más bien ruido" (mujer universitaria). También fueron muchos (25\%) quienes afirmaron que ningún género musical les enoja. 
Tabla 15. ¿Qué tipo de música te produce tristeza?

\begin{tabular}{|c|c|c|c|c|c|c|c|c|c|c|c|c|c|c|c|}
\hline \multirow[b]{2}{*}{ Género musical } & \multicolumn{3}{|c|}{ Secundaria } & \multicolumn{3}{|c|}{ Bachillerato } & \multicolumn{3}{|c|}{ Universidad } & \multicolumn{2}{|c|}{ Hombres } & \multicolumn{2}{|c|}{ Mujeres } & \multicolumn{2}{|c|}{ Total } \\
\hline & Hombres & Mujeres & Total & Hombres & Mujeres & Total & Hombres & Mujeres & Total & Número & Porcentaje & Número & Porcentaje & Número & Porcentaje \\
\hline Bachata & - & 1 & 1 & - & - & - & - & - & - & - & - & 1 & $2,78 \%$ & 1 & $1,27 \%$ \\
\hline Baladas/Bolero/Trova/ Románticas & 5 & 1 & 6 & 4 & 4 & 8 & 8 & 4 & 12 & 17 & $39,53 \%$ & 9 & $25,00 \%$ & 26 & $32,91 \%$ \\
\hline Banda & 2 & - & 2 & 1 & 1 & 2 & 1 & - & 1 & 4 & $9,30 \%$ & 1 & $2,78 \%$ & 5 & $6,33 \%$ \\
\hline Blues & - & - & - & - & - & - & - & 1 & 1 & - & - & 1 & $2,78 \%$ & 1 & $1,27 \%$ \\
\hline Clásica/Ópera & - & - & - & - & - & - & 1 & 4 & 5 & 1 & $2,33 \%$ & 4 & $11,11 \%$ & 5 & $6,33 \%$ \\
\hline Instrumental/Violín & - & 1 & 1 & - & 1 & 1 & 1 & - & 1 & 1 & $2,33 \%$ & 2 & $5,56 \%$ & 3 & $3,80 \%$ \\
\hline $\begin{array}{l}\text { Música triste/Canciones de } \\
\text { desamor }\end{array}$ & - & - & - & 2 & 1 & 3 & - & 1 & 1 & 2 & $4,65 \%$ & 2 & $5,56 \%$ & 4 & $5,06 \%$ \\
\hline Pop & 2 & 5 & 7 & 2 & - & 2 & - & 1 & 1 & 4 & $9,30 \%$ & 6 & $16,67 \%$ & 10 & $12,66 \%$ \\
\hline Rap & 1 & 2 & 3 & - & - & - & - & - & - & 1 & $2,33 \%$ & 2 & $5,56 \%$ & 3 & $3,80 \%$ \\
\hline Rock/Metal/Alternativa & 2 & 2 & 4 & 2 & 3 & 5 & - & - & - & 4 & $9,30 \%$ & 5 & $13,89 \%$ & 9 & $11,39 \%$ \\
\hline Ninguna & 3 & 1 & 4 & 3 & 1 & 4 & 3 & 1 & 4 & 9 & $20,93 \%$ & 3 & $8,33 \%$ & 12 & $15,19 \%$ \\
\hline Total & 15 & 13 & 28 & 14 & 11 & 25 & 14 & 12 & 26 & 43 & $100 \%$ & 36 & $100 \%$ & 79 & $100 \%$ \\
\hline
\end{tabular}

Fuente: Elaboración propia con base en cuestionarios de grupos focales.

Por otra parte, para casi un tercio de la muestra interrogada (32,91\%) las baladas/boleros/trova/románticas -también reagrupadas- provocan tristeza (Cuadro 15). Una joven universitaria mencionó:

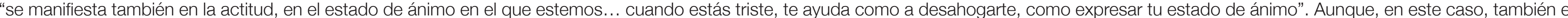
"ninguna" es importante (14,29\%). 
Tabla 16. ¿Qué tipo de música te quita la energía?

\begin{tabular}{|c|c|c|c|c|c|c|c|c|c|c|c|c|c|c|c|}
\hline \multirow[b]{2}{*}{ Género musical } & \multicolumn{3}{|c|}{ Secundaria } & \multicolumn{3}{|c|}{ Bachillerato } & \multicolumn{3}{|c|}{ Universidad } & \multicolumn{2}{|c|}{ Hombres } & \multicolumn{2}{|c|}{ Mujeres } & \multicolumn{2}{|c|}{ Total } \\
\hline & Hombres & Mujeres & Total & Hombres & Mujeres & Total & Hombres & Mujeres & Total & Número & Porcentaje & Número & Porcentaje & Número & Porcentaje \\
\hline Balada/De amor & 1 & 2 & 3 & 1 & - & 1 & 2 & 1 & 3 & 4 & $8,70 \%$ & 3 & $6,67 \%$ & 7 & $7,69 \%$ \\
\hline Banda/Rancheras & - & - & - & - & - & - & 3 & - & 3 & 3 & $6,52 \%$ & - & - & 3 & $3,30 \%$ \\
\hline Blues & - & - & - & 1 & 1 & 2 & - & - & - & 1 & $2,17 \%$ & 1 & $2,22 \%$ & 2 & $2,20 \%$ \\
\hline Clásica/Ópera & - & 1 & 1 & 3 & 3 & 6 & 1 & - & 1 & 4 & $8,70 \%$ & 4 & $8,89 \%$ & 8 & $8,79 \%$ \\
\hline Cumbia & - & - & - & - & - & - & 1 & - & 1 & 1 & $2,17 \%$ & - & - & 1 & $1,10 \%$ \\
\hline Electrónica & - & - & - & - & - & - & 1 & - & 1 & 1 & $2,17 \%$ & - & - & 1 & $1,10 \%$ \\
\hline Instrumental & 1 & - & 1 & - & - & - & 3 & 4 & 7 & 4 & $8,70 \%$ & 4 & $8,89 \%$ & 8 & $8,79 \%$ \\
\hline Jazz & - & - & - & - & - & - & - & 1 & 1 & - & - & 1 & $2,22 \%$ & 1 & $1,10 \%$ \\
\hline Música triste/Ritmo lento & 3 & 7 & 10 & 1 & 2 & 3 & - & - & - & 4 & $8,70 \%$ & 9 & $20,00 \%$ & 13 & $14,29 \%$ \\
\hline Pop & - & - & - & - & 1 & 1 & - & 1 & 1 & - & - & 2 & $4,44 \%$ & 2 & $2,20 \%$ \\
\hline Rap & - & - & - & 1 & - & 1 & - & - & - & 1 & $2,17 \%$ & - & - & 1 & $1,10 \%$ \\
\hline Reggae & - & - & - & 1 & - & 1 & - & - & - & 1 & $2,17 \%$ & - & - & 1 & $1,10 \%$ \\
\hline Reggaeton & 5 & 2 & 7 & 2 & 1 & 3 & 2 & - & 2 & 9 & $19,57 \%$ & 3 & $6,67 \%$ & 12 & $13,19 \%$ \\
\hline Rock/Metal & 2 & 2 & 4 & 1 & - & 1 & 1 & 1 & 2 & 4 & $8,70 \%$ & 3 & $6,67 \%$ & 7 & $7,69 \%$ \\
\hline Ninguna & 4 & 4 & 8 & 2 & 4 & 6 & 3 & 7 & 10 & 9 & $19,57 \%$ & 15 & $33,33 \%$ & 24 & $26,37 \%$ \\
\hline Total & 16 & 18 & 34 & 13 & 12 & 25 & 17 & 15 & 32 & 46 & $100 \%$ & 45 & $100 \%$ & 91 & $100 \%$ \\
\hline
\end{tabular}

Fuente: Elaboración propia con base en cuestionarios de grupos focales.

Finalmente, la música que les quita la energía sería para un 14,29\% la triste o de ritmo lento. Para el 13,19\%, el reggaeton. Sin embargo, hay que tomar en cuenta que un 26,37\% afirmó que ninguna

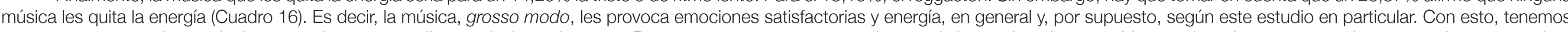

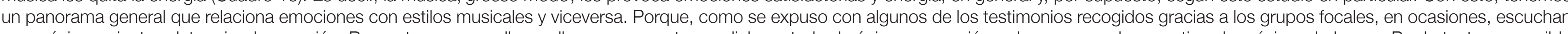

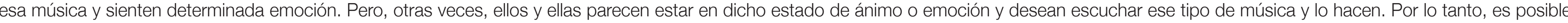
concluir que se trata de una relación bidireccional. 
Eso sí, las y los adolescentes y jóvenes consultados tienen claro la afectación e influencia de la música en sus sentimientos y en su vida. Por ejemplo, un joven de la universidad declara, durante el grupo de enfoque, que:

afecta al subconsciente, muchas veces, lo van a notar mucho las personas. Por eso, yo siempre he dicho, "qué música escuchas y vas a tener una personalidad", la mayoría de las veces así es, porque el género de música que te gusta, afecta hasta el cómo te vistas. El artista o el cantante que te gusta, pues, también es a quién quieres imitar, sí es algo importante en la personalidad del individuo (comunicación personal, 2017).

No obstante, otro joven estudiante universitario dijo:

la música puede probar todas las emociones, depende de la persona, no del género. Por ejemplo, a mí me gusta el reggaetón y la banda y no define mi personalidad, no me visto como ranchero o como reggaetonero y me encanta (comunicación personal, 2017).

Algunos testimonios señalan la importancia de la música para vivir una infancia feliz. Como ilustración, se encuentra el relato de una joven universitaria expuesto durante el grupo focal:

yo creo que los beneficios de la música se dan a temprana edad, creo que hay música para cada tipo de edad. Yo siento que soy una persona feliz o tuve una muy buena infancia, una muy feliz, porque me gustaba escuchar a Cri-cri y a Cepillín, La vecindad del chavo, Tatiana, Confeti, o sea, todos esos grupos que hacían que tú vivieras una niñez feliz. Ahorita hacen que los niños escuchen música de grandes, ellos todavía no llegan a comprender el alcance, tal vez de la letra, porque, a veces, hay niños que están tarareando una canción que, para muchas personas, es ofensiva o como dice un compañero, exalta la violencia y, pues, todo eso se va quedando en la mente del niño, después lo va a reflejar cuando sea una persona adulta (comunicación personal, 2017).

Sobre el tema, ya se ha mencionado la afectación de la música desde el mismo feto y cómo esta se sabe que, bien empleada, resulta sanadora y terapéutica. Aunque como el anterior testimonio afirma, a veces no se es consciente de la música, especialmente, la letra, que escucha la infancia (Fernández, 2005). Lo mismo podríamos afirmar de la población adulta (Fernández, 2002). En el grupo de enfoque universitario, al hablar de emociones relacionadas con los géneros musicales, en ocasiones hubo opiniones diversas y diferentes, No enfrentamientos, pero, sí naturales contrastes entre unos y otros, por lo que, sabiamente, una muchacha, en un momento dado, expresó al respecto: 
como un pequeño paréntesis, creo que la música no nos tiene que comparar porque tenemos amigos que son de rap o escuchan metal, ellos no dejan de ser nuestros amigos, ¿por qué separarnos o hacer grupos de raperos u otros? Pues no, hay que respetar los gustos (comunicación personal, 2017).

Hubo quien señaló "yo, personalmente, tolero todo tipo de música, pero, la que me da paz cuando estoy haciendo la tarea escucho a Frank Sinatra y cuando estoy en casa mucho la música electrónica, escucho pop coreano y otras". Otro más, en el mismo sentido indicó: "dicen que en los gustos se rompen los géneros. No me gusta generalizar con la música, a mí me gusta todo". Finalmente, un testimonio más en el grupo por parte de un joven universitario, que reitera la importante influencia de la música en los seres humanos: "yo siento que la música tiene que ver con la programación neurolingüística, sí afecta de alguna manera tu manera de pensar". Así que, en diferentes relatos se considera la influencia de la música en las personas de una forma importante. Eso sí, según este estudio, generalmente, en el sentido agradable, satisfactorio y positivo.

La música nos sirve para recordar experiencias pasadas, buenas o malas...la melodía la podemos relacionar con alguna vivencia que tuvimos, creo que hay personas que implícitamente le asignamos una canción en específico, entonces cuando la oyes hay veces que te hace recordar a la persona o a la situación, entonces creo que también nos sirve para eso, para que nuestra memoria se ponga a trabajar ¿no? (mujer universitaria, comunicación personal, 2017).

Ciertamente, la música y la emoción están relacionadas con la memoria, de hecho, la emoción es el "pegamento" de la memoria. Mientras que la música evoca recuerdos de personas y situaciones; de vivencias personales y colectivas, con cierta coloración e intensidad. En este mismo sentido habla un hombre universitario: "es como un transportador que te remonta a alguna canción que hayas escuchado en algún momento de tu vida. Cuando la vuelves a escuchar te transporta en el tiempo, a ese momento específico". También, es creación, imaginación y proyección hacia el futuro, como ya se ha visto.

\section{Razonamientos y sentires, explicaciones y comprensiones}

Otro punto abordado en los grupos focales, que decidimos traer aquí con objeto de ir cerrando este trabajo, es el de qué políticas podría aplicar el gobierno u organizaciones sociales para que la música llegue a la ciudadanía. Ahí, apareció una lluvia de ideas sobre las que destacaremos brevemente algunas, las más reiteradas. En general, en secundaria y CCH se apuntó que "haya más conciertos" y "gratuitos" de "diferentes tipos de música", "difundirla por diversos medios de forma gratuita" o "que regalaran discos a todo el mundo". Incluso, "que mientras estudiamos haya música" y "música en todos lados". Otras personas dijeron "poner escuelas de música gratuitas y no reprimir a los músicos". En todo caso, el 
clamor popular, por así decirlo, es: "que haya más conciertos" y "que la música sea gratis". Por otra parte, en la universidad se concretó:

Yo creo que todos, en algún momento, en nuestros primeros grados de vida escolar llevamos música... en cierto grado se deja de lado. La música es clave para la cultura, despierta el alma, despierta habilidades que puedes desempeñar como estudiante. Creo que se pueden implementar muchas cosas para que los niños, los jóvenes y los adultos puedan desarrollarse: más programas de difusión, de baile, de danza (2017).

Aunque no todos parecieron estar de acuerdo, pues hubo quien afirmó "más que dar clases obligatorias, es que existan clases de música para quienes en verdad lo deseen, no todos comparten esa habilidad. Además, provocaría que se viera como obligación y, por tanto, crearía resistencias". En general, se recabaron opiniones favorables a políticas públicas que potencien la música, especialmente, entre infantes y jóvenes. Algunas intervenciones fueron en la línea de "fomentar o hacer proyectos"; "ya hay escuelas públicas en las cuales puedes tocar violín, guitarra, cantar"; "propondría hacer más festivales como Ollin Kan" y "espacios culturales, más que de música, que unan diferentes artes". Si bien también hubo quien consideró que: "hay prioridades más allá de generar una política pública en torno a la música. Existen primeras necesidades que deberían abordarse" dijo un joven universitario.

Finalmente, la música es, en fin, "un arte", "un potenciador de la vida" y "despierta el alma", como expresaron algunos jóvenes. Varias personas señalaron, en los grupos focales, que se trata de "una expresión artística" que "a todo mundo gusta" y "te acompaña toda la vida". Además, apuntaron que "es un lenguaje universal, pues une a todos de cierta manera. Tiene esa función de unir, al llegar a un lenguaje más allá de las palabras y del idioma". Además, "crea identidad" y, con ella, "socializas e intercambias con otras personas". En todo caso, la música mitiga la tempestad emocional y calma la marea sentimental. Una chica del grupo de universitarios remite a Schopenhauer al indicar que "las artes sirven para mitigar el sufrimiento de las personas". En este caso, como dijo Nietzsche, "el mundo sería un error sin música".

\section{Conclusiones}

La música, las emociones y la juventud se encuentran íntimamente ligadas, según pensábamos inicialmente y se ha comprobado de forma total. Incluso, aún más: la música es movimiento y emoción también. De ahí que los campos semánticos y, de manera particular, el emocional esté constituido, en buena parte, por verbos. El empleo de la técnica de investigación de grupos focales y cuestionarios, así como de análisis a través de los campos ellos, ha resultado fructífera en esta investigación. Esto debido a que ha permitido 
un análisis e interpretación frescas y fluidas que, incluso, desbordó las ideas y objetivos iniciales, al conducir a importantes hallazgos inesperados.

También, la música gusta a todo mundo y a todo mundo afecta o influye. Es más, la música es considerada medicina. Además, al parecer, es acompañante y facilitadora de la regulación emocional; equilibra y armoniza, sana y ayuda, hasta el alma, como se señaló. Esta es la conclusión más destacada a la que llegamos en estas páginas. Si las emociones son aprehendidas desde la perspectiva evolucionista, fisiológica, cognitiva y culturalista (André \& Lelord, 2012), la música también tiene que ver con estas. Es más, según Goleman (1995) las emociones conjugan pensar cognitivo-perceptivo, sentir neurofisiológico y comportamental-motivaciones-acciones, lo cual también parece estar íntimamente relacionado con la música, como se ha visto a lo largo de este texto.

La conclusión sobre la función de la música es positiva, mayoritariamente, con algunas excepciones. En general se enfatiza en el campo emocional, sin desconocer también el cognitivo -"ayuda a pensar"- y el comportamental -"ayuda a hacer cosas"-. Sobre el primero, lo que más se valora, por un lado, es la relajación que produce, por otro, la producción de energía: dos opuestos como campos semánticos, aparentemente. No obstante, lo que buscan ambos es la armonía o equilibrio emocional, que aquí denominamos regulación. Esto a través del tono y la intensidad, así como el cambio emocional, repetimos, por medio de la citada armonía y el reiterado equilibrio.

Se comprueban las ideas iniciales y se alcanzan los objetivos propuestos, sobre todo, en la importancia de la música en la vida de las y los jóvenes -seguramente, como en la vida de casi todo ser humano-. También cómo esta destaca en el espacio emocional por sobre otros ámbitos de la vida, tales como el cognitivo y el comportamental, aunque, también tiene incidencia en los mismos, por supuesto. Por otra parte, influye a través del tono y la intensidad en el cambio emocional, nuevamente, por medio de la armonía y el equilibrio. Asimismo, se aportó información sobre las emociones concretas que despiertan la música, según estilo musical. Por ejemplo, la música clásica suele tranquilizar; el género pop, alegrar; la romántica entristece y el reggaetón enoja. Además, la que más energiza es la electrónica, seguida por el rock. Ninguna quita la energía o, en todo caso, un poco la triste. Todo esto, a través del análisis e interpretación de los grupos focales y, especialmente, los cuestionarios aplicados en estos.

No obstante, se debe subrayar que, más allá de estos puntos que se espera haber dejado claros, la información recabada señala que la importancia de la música en las emociones es considerada fundamental y funcional. Gusta y sirve para regular y equilibrar. Esto es, tiene una función social de enorme trascendencia, en tanto socialización, y también terapéutica, más allá de la diversión, el recreo o disfrute que puede proporcionar. Este 
hallazgo hay que remarcarlo, pues, va más allá de lo que se consideró en un principio: lo contiene y lo traspasa al mismo tiempo. La juventud consultada razona y siente; explica y comprende de forma consciente la influencia musical en su cotidianidad, especialmente, de manera favorable, positiva, agradable y satisfactoria. Es consciente de la función social de la música y de su trascendencia emocional, la cual se acompaña y ayuda de la misma. La música es terapéutica y cura según la medicina y la psicoterapia (Sacks, 2015; Jourdain, 2008; Waisburd \& Erdmenger, 2007; Muñoz, 2008). Las personas que formaron parte del estudio, aquí presentado, lo saben y lo utilizan de manera saludable en sus vidas, en la medida de lo posible, por supuesto.

En fin, como varios adolescentes y, sobre todo, los jóvenes universitarios señalan: "la música estabiliza", "equilibra" y "armoniza" emociones. De ahí el título que menciona y anuncia la "regulación emocional". Como también varios sugieren y puede tomarse como cierre de este texto, a modo de recomendación, se precisan más políticas públicas que fomenten la música, ya sea en la escolarización o en otros ámbitos. Se necesitan espacios culturales y proyectos sociales en torno a la misma, pues la música es arte y vida, como dijeron; acompaña y equilibra como subrayaron. Finalmente, hay que decir que, en la actualidad, se está expandiendo el campo de estudio de las Ciencias Sociales, en general. Desde la transdisciplina se encuentran nuevos objetos de estudio, que pudieron estar descuidados o desvalorizados, anteriormente, uno de ellos es la relación de la música con las emociones, que parece ser emergente en nuestros días y posee un futuro prometedor.

\section{Referencias}

Alaminos, A.F. (2014). La música como lenguaje de las emociones. Un análisis empírico de su capacidad performativa. Revista de Ciencias Sociales, 9(1), 15-42.

Alcalde, J. (2017). Cómo nos transforma la música. Recuperado de https://www.muyinteresante.es/salud/articulo/como-nos-transforma-la-musica

André, Ch. \& Lelord Fr. (2012). La fuerza de las emociones. Barcelona: Kairós.

Ball, P. (29 de abril del 2014). El efecto liberador de la música en las emociones. BBC. Recuperado de: http://www.bbc.com/mundo/noticias/2014/04/140429_salud_musica_placer_aa

Barajas, M. (13 de julio del 2016). Por qué nos gusta la música que nos gusta. Las preferencias culturales podrían tener una base cultural. El Mundo. Recuperado de https://www.elmundo.es/ciencia/2016/07/13/57860e5c46163fa9078b4651.html

Bruner, J. S. (1991). Actos de significado: más allá de la revolución cognitiva. Madrid: Alianza.

ESCENA. Revista de las artes, 2019, Vol. 79, Núm. 1 (julio-diciembre), pp. 25-58 
Carballo, P. (2006). La música como práctica significante en los colectivos juveniles. Revista de Ciencias Sociales, III-IV(113-114), 169-176.

Corrales, C. (1991). El estudio de los campos semánticos. Revista de Filología, 10, 79-93.

De la Torre, S. (2012). Dimensión emocional y estilos de vida. Recuperado de https:// docobook.com/dimension-emocional-y-estilos-de-vida-ubedu.html

Fernández, A. M. (2002). Pero vas a estar muy triste y así te vas a quedar. México: INAH.

Fernández, A.M. (2003). Cultura política y jóvenes en el umbral del nuevo milenio. México: IFE/SEP/IMJ.

Fernández, A.M. (2005). Canción infantil: discurso y mensajes. Barcelona: Anthropos.

Fernández, A.M. (2009). La investigación social. México: Trillas.

Fernández, A.M. (2011). Antropología de las emociones y teoría de los sentimientos. Versión Media, 26, Recuperado de https://es.scribd.com/doc/143345258/Antropologia-de-Las-Emociones-y-Teoria-de-Los-Sentimientos

Goleman, D. (1995). La inteligencia emocional. Barcelona: Vergara.

Hormigos, J. \& A. Martín, C. (2004). La construcción de la identidad juvenil a través de la música. Revista Española de Sociología (4). Recuperado de http://www.fes-sociologia.com/files/res/4/11.pdf

Ibáñez, J. (1986). Más allá de la sociología. El grupo de discusión: técnica y crítica. Madrid: Siglo XXI.

Jankélevitch, V. (2005). La música y lo infalible. Barcelona: Alpha Decay.

Jourdain, R. (2008). The Brain, And Ecstasy. London: Harper Perennial.

León, J. (2011). El poder de la música: plenitud, buena salud y gozo espiritual. Miami: Christian Editing.

Manes, F. ( 14 de setiembre del 2015). ¿Qué hace la música a nuestro cerebro? El País. Recuperado de https://elpais.com/elpais/2015/08/31/ciencia/1441020979_017115. html

Morin, E. (1999). El método. El conocimiento del conocimiento. Madrid: Cátedra.

Muñoz, V. (2008). Musicoterapia humanista: uno modelo de psicoterapia musical humanista. México: Libra. 
Oliveira, J. (22 de septiembre de 2017). ¿Para qué sirve la música? Recuperado de https://www.bbvaopenmind.com/para-que-sirve-la-musica

Ortí, A. (1996). La apertura y el enfoque cualitativo o estructural: la entrevista abierta semidirectiva y la discusión en grupo. En García, M.; Ibáñez, J.; Alvira, Fr. (Comp.), El análisis de la realidad social. Métodos y técnicas de investigación. Madrid: Alianza Universidad.

Punset, E. (2011). Música, emociones y neurociencia. REDES. Recuperado de http:// www.rtve.es/television/20111009/musica-emociones-neurociencia/465379.shtml

Real Academia Española. (2018). Música. Recuperado de https://dle.rae.es/?id=Q9MHI5m

Saks, O. (2015). Musicofilia. Relatos de la música y el cerebro. Barcelona: Anagrama.

Smorti, A. (2001). El pensamiento narrativo. Construcción de historias y desarrollo del conocimiento social. Sevilla: Mergablum.

Van Dijk, T. (2001). El discurso como interacción en la sociedad. En Teun Van Dijk, (Comp.) El discurso como interacción social. Barcelona: Gedisa.

Waisburd, G. \&. Erdmenger (2007). El poder de la música en el aprendizaje. México: Trillas. 


\section{Anexo}

Tabla 17. Resumen General

\begin{tabular}{|c|c|c|c|c|c|c|c|c|c|c|c|c|}
\hline Géneros Musicales & & anquilidad & & gría & & gizar & & energía & & jо & & eza \\
\hline Bachata & - & - & - & - & - & - & - & - & - & - & 1 & $1,27 \%$ \\
\hline Baladas/Trova/De amor/Bolero/Románticas & 6 & $7,32 \%$ & 6 & $7,50 \%$ & - & - & 7 & $7,69 \%$ & - & - & 26 & $32,91 \%$ \\
\hline Banda/Rancheras/Corridos & 2 & $2,44 \%$ & 2 & $2,50 \%$ & 1 & $1,12 \%$ & 3 & $3,30 \%$ & 16 & $19,05 \%$ & 5 & $6,33 \%$ \\
\hline Blues & 1 & $1,22 \%$ & - & - & - & - & 2 & $2,20 \%$ & - & - & 1 & $1,27 \%$ \\
\hline Clásica/Ópera & 22 & $26,83 \%$ & 1 & $1,25 \%$ & 1 & $1,12 \%$ & 8 & $8,79 \%$ & 1 & $1,19 \%$ & 5 & $6,33 \%$ \\
\hline Cumbia/Salsa & - & - & 7 & $8,75 \%$ & 1 & $1,12 \%$ & 1 & $1,10 \%$ & 2 & $2,38 \%$ & - & - \\
\hline $\begin{array}{l}\text { Electrónica/Techno/ Psycho/Deep House/ House/ } \\
\text { Trance/Dance/ Minimal }\end{array}$ & 8 & $9,76 \%$ & 22 & $27,50 \%$ & 43 & $48,31 \%$ & 1 & $1,10 \%$ & - & - & - & - \\
\hline Folclore & 1 & $1,22 \%$ & - & - & - & - & - & - & - & - & - & - \\
\hline Instrumental/Violín & 2 & $2,44 \%$ & - & - & - & - & 8 & $8,79 \%$ & - & - & 3 & $3,80 \%$ \\
\hline Jazz & 10 & $12,20 \%$ & - & - & 1 & $1,12 \%$ & 1 & $1,10 \%$ & - & - & - & - \\
\hline Música triste/ Ritmo lento/ Canciones de desamor & - & - & - & - & - & - & 13 & $14,29 \%$ & - & - & 4 & $5,06 \%$ \\
\hline Pop/ K-pop/Melódica & 6 & $7,32 \%$ & 8 & $10,00 \%$ & 4 & $4,49 \%$ & 2 & $2,20 \%$ & 2 & $2,38 \%$ & 10 & $12,66 \%$ \\
\hline Protesta & - & - & 1 & $1,25 \%$ & - & - & - & - & 1 & $1,19 \%$ & - & - \\
\hline$R \& B$ & - & - & 3 & $3,75 \%$ & - & - & - & - & - & - & - & - \\
\hline Rap/Hip-hop & 7 & $8,54 \%$ & 2 & $2,50 \%$ & 6 & $6,74 \%$ & 1 & $1,10 \%$ & 3 & $3,57 \%$ & 3 & $3,80 \%$ \\
\hline Reggae & 3 & $3,66 \%$ & 2 & $2,50 \%$ & - & - & 1 & $1,10 \%$ & - & - & - & - \\
\hline Reggaeton & 2 & $2,44 \%$ & 10 & $12,50 \%$ & 7 & $7,87 \%$ & 12 & $13,19 \%$ & 22 & $26,19 \%$ & - & - \\
\hline $\begin{array}{l}\text { Rock/Metal/Indie/ Punk Rock/Grunge/ Alternativa/ } \\
\text { Rock clásico }\end{array}$ & 10 & $12,20 \%$ & 6 & $7,50 \%$ & 20 & $22,47 \%$ & 7 & $7,69 \%$ & 16 & $19,05 \%$ & 9 & $11,39 \%$ \\
\hline Ska & - & - & 10 & $12,50 \%$ & 2 & $2,25 \%$ & - & - & - & - & - & - \\
\hline Tango & 1 & $1,22 \%$ & - & - & - & - & - & - & - & - & - & - \\
\hline Trap & - & - & - & - & 1 & $1,12 \%$ & - & - & - & - & - & - \\
\hline Urbana & - & - & - & - & 1 & $1,12 \%$ & - & - & - & - & - & - \\
\hline Ninguna & 1 & $1,22 \%$ & - & - & 1 & $1,12 \%$ & 24 & $26,37 \%$ & 21 & $25,00 \%$ & 12 & $15,19 \%$ \\
\hline Total & 82 & $100 \%$ & 80 & $100 \%$ & 89 & $100 \%$ & 91 & $100 \%$ & 84 & $100 \%$ & 79 & $100 \%$ \\
\hline
\end{tabular}

Fuente: Elaboración propia con base en cuestionarios de los grupos focales. 